\title{
Paradoxical electrocardiographic effects of amyl nitrite in coronary artery disease
}

\author{
:Richard E. Kerber and Donald C. Harrison \\ From the Department of Industrial Medicine, University of Iowa Medical Center, Iowa City, Iowa; \\ and Cardiology Division, Stanford University School of Medicine, Stanford, California 94305, \\ U.S.A.
}

The electrocardiographic response to amyl nitrite inhalation was correlated with treadmill stress testing in $6 I$ patients. Eleven patients developed ST depressions suggesting myocardial ischaemia after amyl nitrite inhalation on a total of 17 different occasions. All had positive treadmill tests; 8 had coronary artery disease seen on angiocardiography; I had aortic stenosis, I had lupus, and I had angina with normal coronary arteries. This group was compared with I 5 patients who had : angiographically proven coronary artery disease and positive treadmill tests but negative amyl nitrite tests: the group with positive amyl nitrite tests responded to drug inhalation with a significantly greater heart rate increase $(47 \%$ vs. $34 \%, P<0.01)$, and a significantly greater fall in systolic blood pressure $(42 \%$ vs. $31 \%, P<0.05)$ and diastolic blood pressure $(42 \%$ vs. $29 \%$, $P<0.05)$. Atrial pacing studies in 4 patients suggested that the amyl nitrite induced ischaemic changes were not due to tachycardia alone. No patient with a negative treadmill test had a , positive amyl nitrite test; positive amyl nitrite tests became negative after revascularization surgery, propranolol therapy, or clinical improvement. The paradox of ischaemic electrocardiographic changes caused by amyl nitrite is probably explained by the observed acute reduction of coronary perfusion pressure and abbreviation of diastole. Amyl nitrite may have clinical application in the diagnostic and therapeutic evaluation of coronary artery disease.

Amyl nitrite has long been recognized to be an effective agent in the treatment of angina ' pectoris (Brunton, 1867). Its effects on the phonocardiogram and its haemodynamic actions have been well studied and provide useful diagnostic information in a variety of cardiac lesions (Beck et al., I96I; Cohn, Flamm, and Hancock, 1968; Perloff et al., 1963). Electrocardiographic alterations of - several types after amyl nitrite inhalation have been described (Goldberger, I945; Myburgh, 1969), and it has been suggested that the appearance of these changes may indicate the presence of coronary heart disease (Contro, Haring, and Goldstein, 1952; Varela de Seijas Aguilar et al., I953; Rizzon, Lovreglio, , and Bacca, 1963). These studies were undertaken to evaluate further and attempt to explain the electrocardiographic actions of amyl nitrite, and to correlate these effects with treadmill testing and coronary angiography in the same patients.

Received 6 December 1971.

\section{Subjects and methods}

Sixty-one adult patients were given amyl nitrite a total of 75 times. The initial 30 amyl nitrite tests were performed on any patients undergoing treadmill testing who would consent to the amyl nitrite inhalation. The remaining 45 tests were performed on subjects who had already been shown to have positive treadmill tests. No attempt was made to separate or select patients by age, sex, clinical condition, or other criteria.

After instruction and consent, the patient took four deep breaths without the drug, while an electrocardiogram (leads II and $V_{5}$ simultaneously) was being recorded continuously; recording was continued for at least 2 minutes. This constituted a control period and evaluated the effect of hyperventilation alone. An amyl nitrite pearl was then crushed and held under the patient's nose while the inhalations were repeated and similar electrocardiographic recordings made. Blood pressures obtained by the cuff method were recorded before inhalation, and at the maximal amyl nitrite effect (about 30 seconds). The test was performed in the erect position in all patients, and repeated in the supine position in half the cases. Similar blood pressure and 
electrocardiographic observations were made after sublingual nitroglycerin administration in 10 standing patients, who had previously undergone amyl nitrite inhalation.

Maximal treadmill stress testing, using a modification of the multistage method of Bruce et al. (I963) was performed at least once on all patients. Most patients underwent this test on the same day as the amyl nitrite study; the two tests were separated by at least 15 minutes, and longer if necessary, to allow electrocardiograms to return to the control condition. The electrocardiographic recordings from the two tests were interpreted by independent readers; horizontal ST segment depression of at least $\mathrm{I} \mathrm{mm}$, which persisted for at least $0.08 \mathrm{sec}$ was defined as 'positive' (indicating myocardial ischaemia) for both tests (Master and Rosenfeld, 1967). The amyl nitrite test was compared with both control and hyperventilation tracings when being interpreted. ' $\mathrm{J}$ '-point depression was classified separately. Patients receiving digitalis were excluded (Kawai and Hultgren, I964).

Four patients who had previously undergone treadmill and amyl nitrite testing were studied using atrial pacing during the course of cardiac catheterization. A Goetz bipolar pacing catheter was placed at the junction of the superior vena cava and right atrium, and pacing at rates up to I50 impulses a minute accomplished while external electrocardiograms (leads II and V5 simultaneously) were recorded.

Coronary angiography was performed on 30 of these patients. Significant coronary artery disease was defined by us as at least one lesion in a main coronary artery, resulting in 50 per cent or greater narrowing of the arterial lumen. Most patients had much more severe disease than this. In 2 patients who died before angiography, necropsy evaluation of the coronary arteries was available.

\section{Results}

Nineteen patients had negative treadmill tests. Nine of these patients underwent diag-

FIG. I Electrocardiographic effects of amyl nitrite in a 40-year-old woman with coronary artery disease. Ischaemic $S T$ depressions are present on both amyl nitrite and treadmill testing. $H V=$ hyperventilation, $A N=$ amyl nitrite, $T M=$ treadmill, $C A D=$ coronary artery disease.



A.B. (CAD)

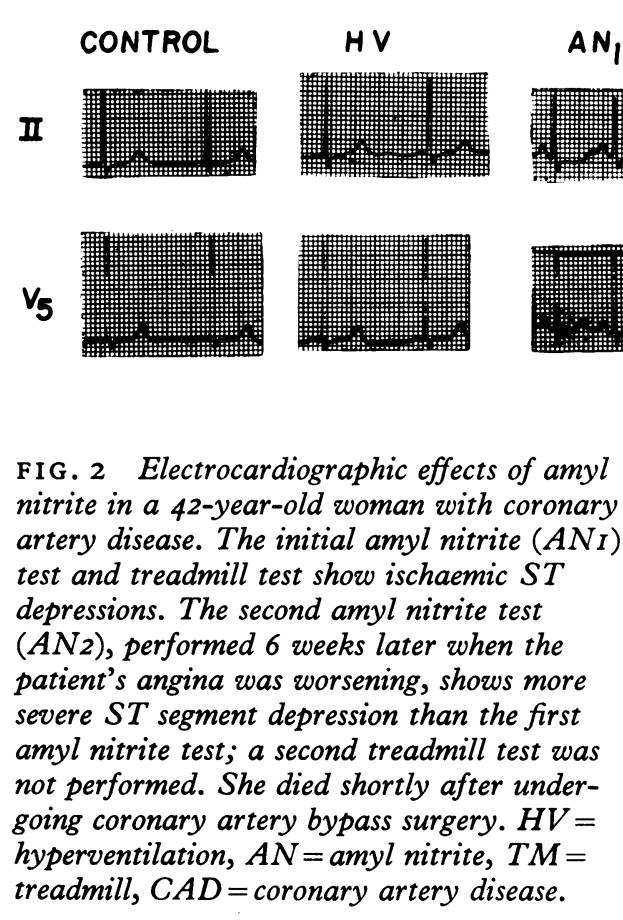

nostic coronary arteriography and 6 were shown to have significant coronary artery disease. All of these 19 had negative amyl nitrite tests; no patient with a negative treadmill test had a positive amyl nitrite test. This group will not be further considered in this paper.

Twenty-eight patients had ischaemic ST

FIG. 3 Electrocardiographic effect of amyl nitrite in a 45-year-old man with coronary artery disease. ANI shows flat ischaemic ST depression in II and V5, while TMI shows ' $f$ '-point depression. Both tests are negative after coronary artery bypass surgery. $H V=$ hyperventilation, $A N=$ amyl nitrite, $T M=$ treadmill, $C A D=$ coronary artery disease.
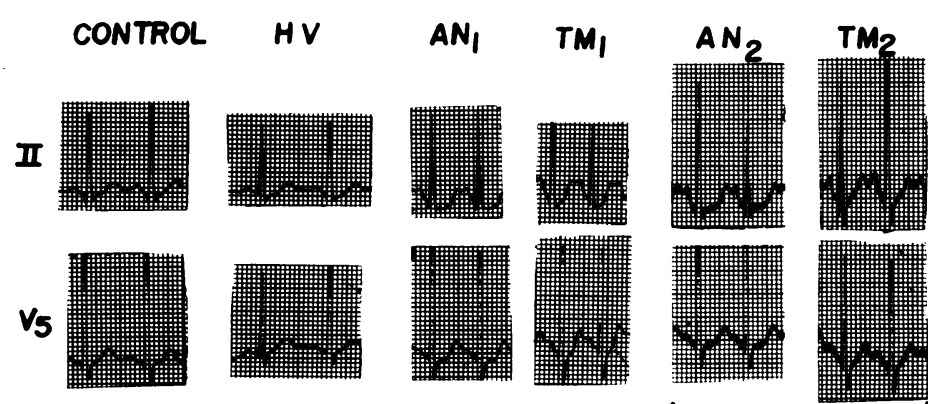

POST OPERATIVE E.O. (CAD)
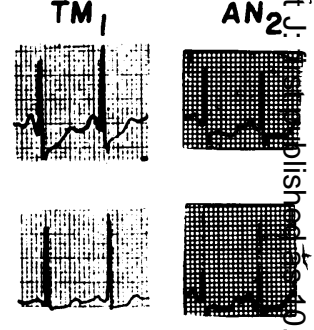

J.F. (CAD) 

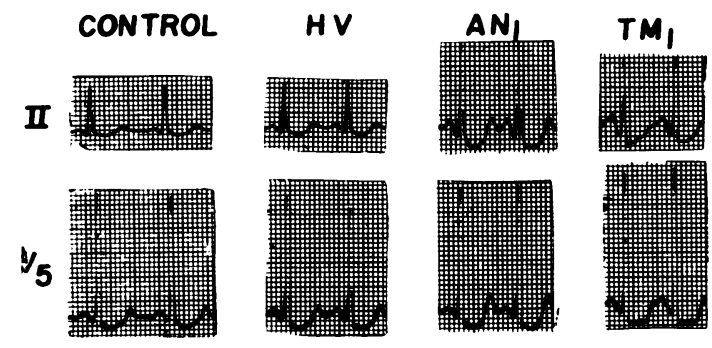
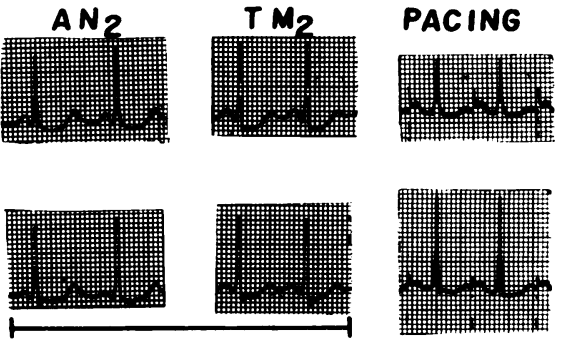

S.S. (ANGINA)

FIG. 4 Electrocardiographic effects of amyl nitrite in a 58-year-old man with clinically typical angina and normal coronary arteries. The first amyl nitrite and treadmill tests show ischaemic ST depressions. (Maximal amyl nitrite rate 126 per minute.) While on propranolol, the maximal amyl nitrite rate was only $90 / \mathrm{min}$, and the test $(A N 2)$ is negative. The second treadmill test (TM2) remains positive. Atrial pacing to a maximal rate of $120 /$ minute fails to induce ischaemic $S T$ depression. $H V=$ hyperventilation; $A N=$ amyl nitrite; $T M=$ treadmill.

depression on treadmill tests, but negative amyl nitrite tests. Eighteen of these patients underwent coronary arteriography; 15 were shown to have significant coronary artery disease (Group A). Eleven patients (Group B) displayed ischaemic ST depression on amyl nitrite inhalation which was reproducible on several occasions; a total of 17 positive amyl nitrite tests was obtained in these II cases (Fig. I-6). Of these II patients, 8 had coronary artery disease, shown angiographically (Fig. I-5). One patient had aortic stenosis with normal coronary arteries, one suffered from clinically typical angina pectoris with angiographically demonstrated normal coronary arteries (Fig. 4), and one had systemic lupus erythematosus (Fig. 6). Of these II patients, Io also had positive treadmill tests; one had ' $\mathrm{J}$ ' depression only on treadmill testing (Fig. 3).

Three additional patients developed ' $\mathrm{J}$ 'point depression after amyl nitrite, as well as on treadmill testing (Fig. 7).

Atrial pacing studies were performed on 4 patients: one with ischaemic ST depressions induced by both amyl nitrite and treadmill tests (Fig. 4); one with ' $\mathrm{J}$ ' depression on both amyl nitrite and treadmill test (Fig. 7); and 2 with positive treadmill tests but negative amyl mitrite tests. The latter 2 were chosen because the maximal heart rates achieved on their negative amyl nitrite test (I IO and IoO beats/ $\mathrm{min}$ ) were considerably slower than the corresponding maximal treadmill rates (130 and 130). These 4 patients were paced to rates equal to or exceeding their maximal amyl nitrite induced rates and/or maximal tread- mill rates. In no case did atrial pacing result in ischaemic ST changes.

Amyl nitrite inhalation produced hypotension and tachycardia in all subjects. This effect was maximal in about 30 seconds after the final inhalation, and was generally gone in I minute. No patient developed chest pain after amyl nitrite. These effects were invariably greater in the standing than in the supine position, and the observed electrocardiographic changes were always more prominent

FIG. 5 Electrocardiographic effects of amyl nitrite in a 48-year-old man with coronary artery disease. ANI and TMI show ischaemic $S T$ depression, especially in lead II. After propranolol therapy, $A N 2$ shows equivocal $S T$ depression in lead II when compared with the hyperventilation (HV) tracing, while $V_{5}$ no longer shows any $S T$ depression greater than the control and hyperventilation tracings. The treadmill test (TM2) remains positive. $H V=$ hyperventilation; $A N=$ amyl nitrite; $T M=$ treadmill; $C A D=$ coronary disease.

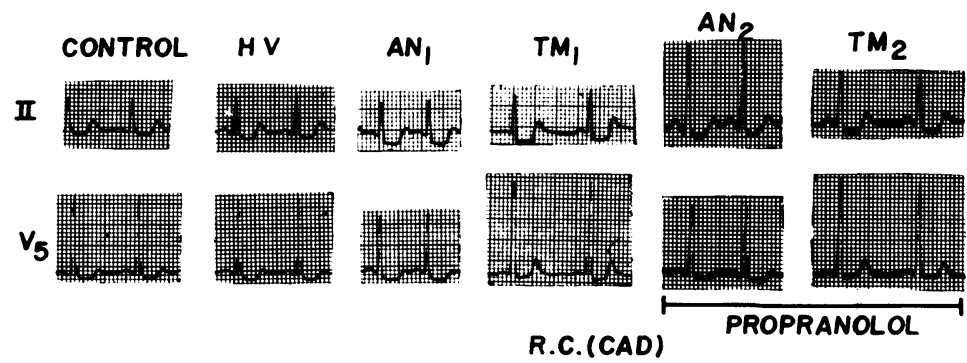


standing than supine. For purposes of statistical analysis, the 15 amyl nitrite tests in Group A patients (coronary artery disease, positive treadmill test, negative amyl nitrite test) were compared with the 17 positive amyl nitrite tests obtained in Group B patients (Fig. 8-II). The mean ages and sex distribution within these two groups were not statistically different. Before amyl nitrite, there were no significant differences between the two groups in heart rate and systolic and diastolic blood pressure. After amyl nitrite inhalation, the Group B patients developed significantly faster maximal heart rates and lower systolic and diastolic blood pressures. The product of heart rate and systolic blood pressure, however, was not significantly different between the two groups, either before or after amyl nitrite.

Three patients with positive amyl nitrite tests underwent repeat amyl nitrite testing while receiving oral propranolol. In all, the blood pressure changes were unaffected, but the mean maximal heart rate attained was reduced from 135 to II I ( $17 \%$ decline) while the patient was receiving propranolol. In I of these 3 patients, the repeat amyl nitrite test performed during the administration of propranolol became negative (Fig. 4), while in a second, the repeat test was equivocal (Fig. 5).

Sublingual nitroglycerin was administered to Io standing patients with coronary artery disease, including 2 with positive amyl nitrite tests. In no instance did the blood pressure or heart rate changes of nitroglycerin approach those induced by amyl nitrite, and no ischaemic electrocardiographic changes occurred.

\section{Discussion}

The initial studies of Contro et al. (1952) and others (Varela de Seijas Aguilar et al., 1953; Rizzon et al., 1963) accepted both ST segment depression and $T$ wave inversion as evidence of amyl nitrite induced myocardial ischaemia. These criteria were too broad, as shown by $T$ wave inversion in a high percentage of young healthy military recruits inhaling amyl nitrite (Myburgh, 1969). T wave inversions alone were therefore not accepted as indicative of myocardial ischaemia in this study. An additional reservation with regard to the validity of the earlier studies was the absence of anatomical or radiological evaluation of the coronary circulation in the ascription of coronary artery disease. Coronary arteriography was therefore performed on as many patients as possible, including ro of the I I patients with positive amyl nitrite tests. In the latter group, only $I$ of the Io patients studied angiographically did not have coron-

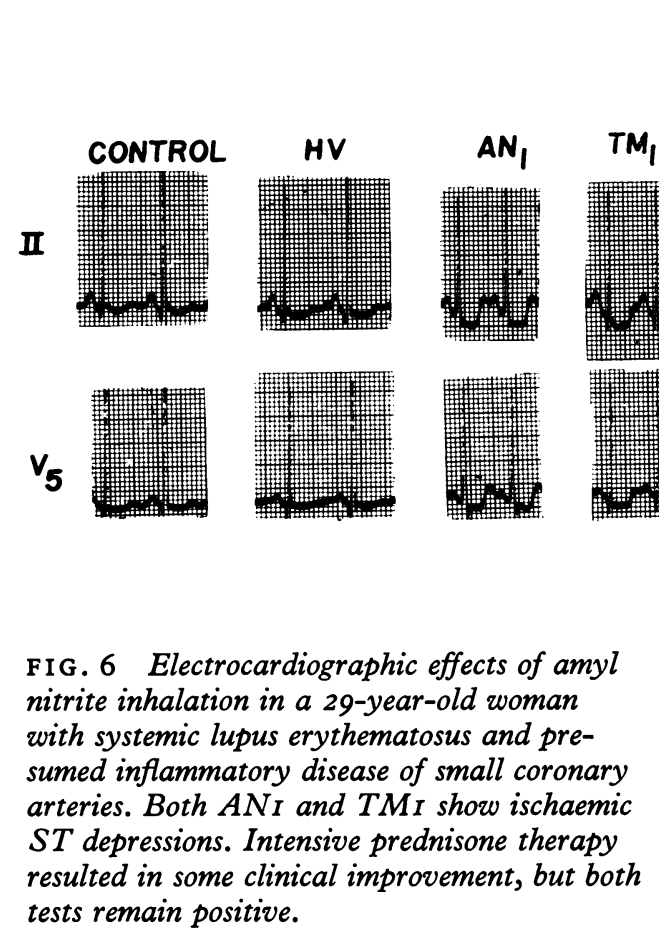

ary artery disease or aortic stenosis; in view of a positive treadmill test, he is considered to have the syndrome of angina with normal coronary arteries (Kemp, Elliott, and Gorlin, 1967). Thus, there is an excellent correlation between anatomical or physiological lesions known to produce myocardial ischaemia, and electrocardiographic ST depression induced by amyl nitrite inhalation. This supports the presumption that the observed electrocardiographic changes are in fact a result of myocardial ischaemia. The failure to elicit chest

FIG. 7 Electrocardiographic effects of amyl nitrite inhalation in a 53-year-old man with coronary artery disease. ' $\mathcal{F}$ '-point depression is present in both control and hyperventilation tracings and is accentuated by both amyl nitrite and treadmill testing (maximal amyl nitrite rate $140 /$ minute). Atrial pacing to I 5o/minute induces only minimal ' $\mathcal{F}$ '-point depression, less than the $A N$ and TM tests. $H V=$ hyperventilation; $A N=$ amyl nitrite; $T M=$ treadmill; $C A D=$ coronary artery disease.

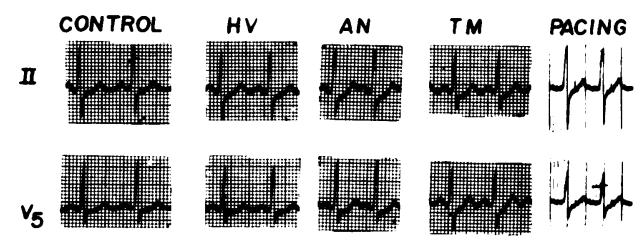

A.S (CAD)

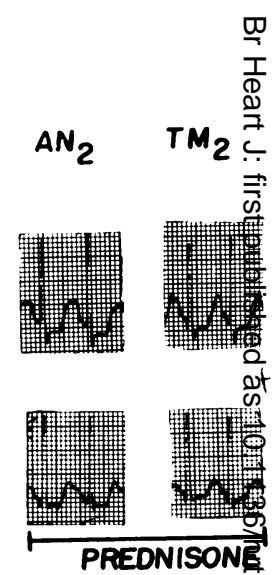

D.N. (SLEF 


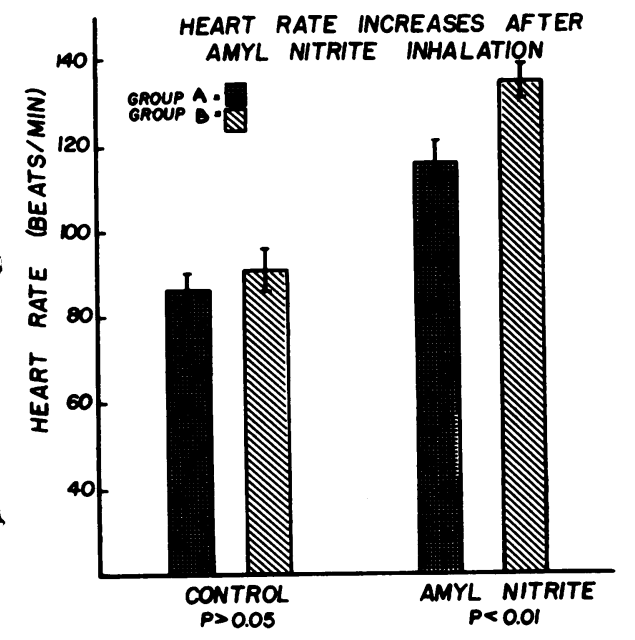

FIG. 8 Heart rates before and after amyl nitrite inhalation in erect patients. Group $A$ patients have coronary artery disease, positive treadmill tests, and negative amyl nitrite tests; Group $B$ patients have positive amyl nitrite tests. There is no significant difference in resting heart rate before amyl nitrite inhalation, while after the drug the maximal heart rate achieved is significantly faster in Group $B$ patients.

$\perp$

pain during any of the positive amyl nitrite tests remains unexplained, but may be related to the very brief duration of the amyl nitrite effects (usually less than one minute). Similar failure of chest pain to accompany ischaemic ST depression has also been reported in a high percentage of patients undergoing maximal treadmill stress testing (Ellestad et al., - r969).

How does amyl nitrite, a vasodilating agent, produce myocardial ischaemia? The inhalation of amyl nitrite results in a conspicuous fall in systemic and pulmonary vascular resistance and a precipitous drop in systemic arterial pressure (Mason and Braunwald, ig65). A reflex venoconstriction and tachycardia ensue, and the cardiac output rises rapidly because of the decreased systemic resistance (afterload) and increased venous return (pre-load), the latter resulting from intense venoconstriction. However, the tendency for the reflex venoconstriction to inxrease the pre-load and work of the ventricle is overbalanced by the greater effect of the - reduced afterload; this results in overall reductions of intraventricular systolic pressure and volume and diminished myocardial tension and oxygen demand (Mason, Zelis, and Amsterdam, I97I). This is the physiological basis for the use of amyl nitrite in the relief of angina pectoris. On the other hand, the fall in diastolic blood pressure results in a conspicuous fall in coronary perfusion pressure. At the same time, tachycardia results in an abbreviation of diastole and coronary blood flow. These factors probably assume additional importance in a diseased coronary vessel with critical luminal stenosis. It has, therefore, been suggested that the amyl nitrite induced rapid fall in blood pressure might, paradoxically, worsen ischaemia in instances where the decline in coronary blood flow is greater than the decrease in myocardial oxygen need (Mason et al., 197I).

This investigation presents evidence to support this hypothesis. It is also supported by comparison of the Group B patients (positive amyl nitrite tests) with Group A patients (coronary artery disease, positive treadmill test, negative amyl nitrite test) with regard to amyl nitrite induced heart rate and blood pressure change. These changes were significantly greater in the patients with positive amyl nitrite tests than those with negative tests. On the other hand, the product of systolic blood pressure and heart rate - a rough indicator of myocardial oxygen requirements - declined about equally in both groups. Thus, amyl nitrite appears to have reduced myocardial oxygen demand to the same degree in both groups of patients; those who develop greater hypotension and tachycardia with the drug presumably incur a fall in coronary blood flow which transiently outweighs the reduced myocardial oxygen demand and results in a temporary period of myocardial ischaemia.

FIG. 9 Systolic blood pressure before and after amyl nitrite inhalation in erect patients. Group B patients achieve a significantly lower minimal systolic blood pressure after amyl nitrite.

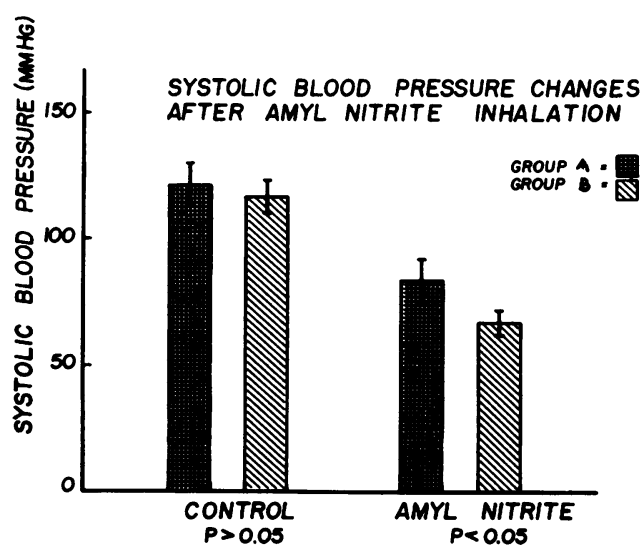




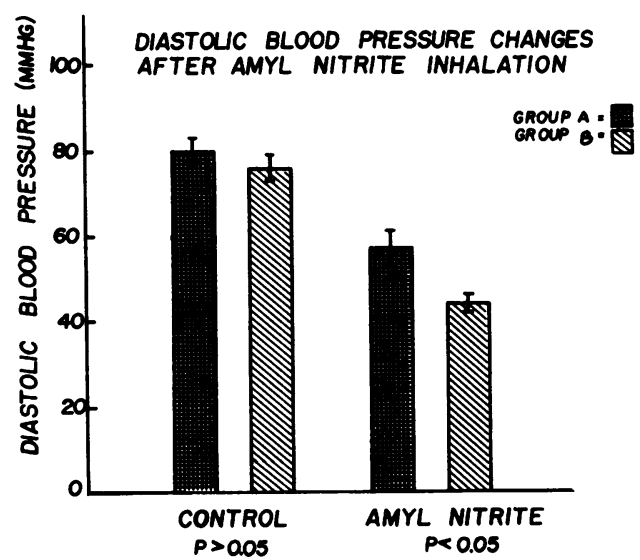

FIG. Io Diastolic blood pressure before and after amyl nitrite inhalation in erect patients. Group B patients achieve a significantly lower minimal diastolic blood pressure after amyl nitrite.

Beta-adrenergic blockade with propranolol modified the amyl nitrite effect by reducing the reflex tachycardia, resulting in less abbreviation of diastole and a longer period of coronary blood flow. In addition, total myocardial oxygen demands are reduced by propranolol (Wolfson et al., I966). Thus, two positive amyl nitrite tests became negative or equivocal after propranolol was instituted. On the other hand, atrial pacing alone to heart rates equivalent to the amyl nitrite induced

FIG. II The product of systolic blood pressure and heart rate in erect patients before and after amyl nitrite inhalation. The drug causes almost equal falls in both groups of patients.



maximal rates did not result in electrocardiographic changes suggesting ischaemia. This is probably because the diastolic blood pressure rose slightly during pacing (the mean diastolic blood pressure rose from 70 to 87 $\mathrm{mmHg}$, a $16 \%$ increase) as the stroke volume fell. Thus, though diastole was abbreviated, coronary perfusion pressure rose rather than fell, and the net reduction in coronary blood flow was less than with amyl nitrite.

Nitroglycerin was reported to exacerbate electrocardiographic changes caused by exercise in 17 of 158 patients tested by Russek, Urbach, and Zohman (1955). However, we were unable to produce ischaemic electrocardiographic change in standing, non-exercising patients by administering sublingual nitroglycerin. The difference between these results and amyl nitrite's effects is probably explained by the observation that nitroglycerin's direct action on the veins producing venodilatation and reduced ventricular preload appears to outweigh its action on the arterioles of decreasing systemic vascular resistance (afterload) (Mason et al., 1971). In contrast, inhaled amyl nitrite enters the circulation much more rapidly, and its predominant effect is on the arterial bed. Hypotension and tachycardia are much less with nitroglycerin than with amyl nitrite (Mason et al., 1971).

From a clinical viewpoint, amyl nitrite probably has application in the therapeutic evaluation of coronary artery disease. Positive amyl nitrite tests were repeatedly positive in patients who were displaying a partial or unsatisfactory response to medical therapy for coronary artery disease (Fig. 2) or, in one case, to corticosteroid therapy for systemic lupus erythematosus (this patient is believed to have inflammatory disease of the small coronary vessels (Brigden et al., 1960), but coronary angiography had not been done) (Fig. 6). In other instances, the test became negative after surgical revascularization (Fig. 3) and propranolol therapy (Fig. 4 and 5), paralleling the results of treadmill testing and clinical improvement in these patients. As noted, there is good correlation between anatomical coronary artery disease and a positive amyl nitrite test; the percentage of false positive tests appears to be low, and probably approximates that of treadmill testing (Master and Rosenfeld, 1967). On the other hand, I5 patients were encountered who had angiographically proven coronary disease and positive treadmill tests, but negative amyl nitrite tests. Thus, the number of false negative amyl nitrite tests is substantial, which limits the diagnostic value of the procedure. It may 
be worth while to perform it for diagnostic purposes in the occasional patient who is unable to undergo exercise stress testing because of a physical disability (amputation, arthritis, etc.); a positive result strongly suggests that treadmill testing and angiographic studies will be abnormal.

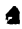

The authors are indebted to Mrs. Utra Nair and $\mathrm{Mr}$. Warren Clark for their enthusiastic co-operation in performing the treadmill and amyl nitrite studies, and to Dr. E. William Hancock for his invaluable advice and criticism in planning this study.

\section{References}

Beck, W., Schrire, V., Vogelpoel, L., Nellen, M., and Swanepoel, A. (196I). Hemodynamic effects of amyl nitrite and phenylephrine on the normal human circulation and their relation to changes in cardiac murmurs. American fournal of Cardiology, 8, 341 .

Brigden, W., Bywaters, E. G. L., Lessof, M. H., and Ross, I. P. (1960). The heart in systemic lupus erythematosus. British Heart fournal, 22, I.

Bruce, R. A., Blackmon, J. R., Jones, J. W., and Strait, G. (1963). Exercising testing in adult normal subjects and cardiac patients. Pediatrics, 32, 742.

Brunton, T. L. (1867). On the use of nitrite of amyl in angina pectoris. Lancet, 2, 97.

Cohn, K. E., Flamm, M. D., and Hancock, E. W. (1968). Amyl nitrite inhalation as a screening test

a for hypertrophic subaortic stenosis. American fournal of Cardiology, 21, 681.

Contro, S., Haring, O. M., and Goldstein, W. (1952). Paradoxic action of amyl nitrite in coronary patients. Circulation, 6, 250.

Ellestad, M. H., Allen, W., Wan, M. C. K., and Kemp, G. L. (1969). Maximal treadmill stress testing for cardiovascular evaluation. Circulation, 39, 517.

Goldberger, E. (1945). The effects of amyl nitrite on the downward $T$ wave of the electrocardiogram. American Heart fournal, 30, 60.

Kawai, C., and Hultgren, H. N. (1964). The effect of digitalis upon the exercise electrocardiogram. American Heart fournal, 68, 409.
Kemp, H. G., Elliott, W. C., and Gorlin, R. (1967). The anginal syndrome with normal coronary arteriography. Transactions of the Association of American Physicians, 80, 59.

Mason, D. T., and Braunwald, E. (1965). The effects of nitroglycerin and amyl nitrite on arteriolar and venous tone in the human forearm. Circulation, 32, 755.

Mason, D. T., Zelis, R., and Amsterdam, E. A. (1971). Actions of the nitrites on the peripheral circulation and myocardial oxygen consumption: significance in the relief of angina pectoris. Chest, 59, 296.

Master, A. M., and Rosenfeld, I. (1967). Two-step exercise test: current status after 25 years. Modern Concepts of Cardiovascular Disease, 36, 19.

Myburgh, D. P. (1969). The effect of amyl nitrite on the electrocardiogram of normal subjects. South African Medical fournal, 43, 517.

Perloff, J. K., Calvin, J., De Leon, A. C., and Bowen, P. (I963). Systemic hemodynamic effects of amyl nitrite in normal man. American Heart fournal, 66, 460.

Rizzon, P., Lovreglio, V., and Bacca, F. (1963). Modificazioni E.C. grafiche indotte dal nitrito d'amile a carico della ripolarizzazione ventricolare: loro valore diagnostico quale test di insufficienza coronarica e loro interpretazione. Folia Cardiologica, 22, 147.

Russek, H. I., Urbach, K. F., and Zohman, B. L. (1955). Paradoxical action of glyceryl trinitrate (nitroglycerin) in coronary patients. Fournal of the American Medical Association, 158, 1017.

Varela de Seijas Aguilar, J., Losada Trulock, E. R., Martin Perez, G., and Herrero Botas, A. (1953). Sobre la objectivacion de la anoxia miocardíca mediante electrocardiogramas obtenidos durante el ejercicio y tras la inhalacion de nitrito de amilo. Revista Española de Cardiologia, 7, 230.

Wolfson, S., Heinle, R. A., Herman, M. V., Kemp, H. G., Sullivan, J. M., and Gorlin, R. (1966). Propranolol and angina pectoris. American fournal of Cardiology, 18, 345.

Requests for reprints to Dr. Donald C. Harrison, Cardiology Division, Stanford University Medical Center, Stanford, California 94305, U.S.A. 